\title{
The Adequacy of Genuine Modal Realism
}

\section{HAROLD W. NOONAN}

University of Nottingham

Harold.noonan@nottingham.ac.uk

\section{Introduction}

What requirements must an adequate genuine modal realist (Lewisean) analysis of modal discourse satisfy? One, obviously, is material adequacy: the modal realist must provide for each candidate analysandum in ordinary modal discourse an analysans in the language of counterpart theory which by his lights has the same truth value as the candidate analysandum. But must the analysandum and analysans be strictly equivalent? Is it a requirement of the adequacy of the analysis that in the eyes of the modal realist each strictly implies the other, that is, that the material biconditional joining them formulated in the language of modal discourse extended (if necessary) ${ }^{1}$ by addition of the predicates 'is a world', 'is a counterpart', 'is actual' and 'is in' be necessarily true, and its necessitation true? Call this the requirement of strict adequacy.

In the following I first point out that the requirement of strict adequacy is not satisfied if Lewis's 1968 translation scheme for the absolute modalities is taken as providing the analysis. The point is an obvious one, and its explanation is the same as that of the fact that according to that translation scheme 'Necessarily, there is only one world' is true by modal realist lights, although the modal realist contention is that there are many worlds (Noonan 1994). A modification of Lewis's translation scheme, which identifies cases of 'advanced modalizing' as special cases in which the modal operator is to be interpreted as semantically

\footnotetext{
${ }^{1}$ Actually, given Lewis's later (after 1968) explanations, synonyms of these predicates are already in ordinary modal discourse, e.g. 'is actual' means 'is spatiotemporally related to me'.
} 
redundant, is put forward by John Divers (1999). On Divers's redundancy interpretation

'Necessarily there is only one world' is assigned the analysis 'There is only one world' and hence comes out as false by modal realist lights, whilst 'Possibly there many worlds' and 'Necessarily there are many worlds' are both equivalent to 'There are many worlds' and true. I argue that even when the rules of the translation scheme are modified as Divers proposes modal realist analysis of statements of modal discourse will still be strictly inadequate (though materially adequate) in the eyes of the modal realist.

Strict adequacy of a modal realist analysis of modal discourse can be achieved, however, on an approach that extends the redundancy interpretation to all de dicto modal statements. The price the modal realist must pay for this is the denial of de dicto contingency. But maybe this is a price worth paying, or no great price at all.

Even if this is not so, I will not argue that this is a problem for modal realism. Perhaps something less than strict adequacy is enough. Perhaps, if the modal realist has a systematic means of replacing every sentence of quantified modal logic which he considers true by a sentence of counterpart theory that he considers true, he need do no more. ${ }^{2}$ Still, traditionally philosophical analysis aims at strict adequacy so that it is as well to know that this is a test the modal realist analysis of modal discourse fails unless de dicto contingency is abandoned.

\section{The problem for the modal realist and Divers's solution}

The point that according to Lewis's original 1968 translation scheme the modal realist analysis is not strictly adequate is easy to see.

\footnotetext{
${ }^{2}$ But, as an anonymous referee has impressed upon me: 'Everything here depends on what is meant by "systematic". Let $\mathrm{T}$ and $\mathrm{F}$ be a tautology and a contradiction respectively in the language of counterpart theory. What if the modal realist announces that every true sentence of quantified modal logic is to be mapped onto $\mathrm{T}$ and very false sentence to F? That is systematic in a way, and all the resulting material biconditionals are true. If the language of modal logic is sufficiently restricted it may even admit of a decision procedure, in which case the mapping can be made recursive.' So the occurrences of 'perhaps' in the text should not be ignored. The modal realist who retains de dicto contingency cannot require strict adequacy in his paraphrases, but he presumably must intend more than mere material adequacy. As should be evident I think that developing an account that denies de dicto contingency is a more promising route for the modal realist.
} 
Lewis's translation of 'Possibly there are talking donkeys' into the language of counterpart theory is 'There is a possible world in which there is a talking donkey'. Lewis thinks that this is true; he believes that there is a world part of which is a talking donkey. Because he is a commonsensical fellow he also thinks true the statement of quantified modal logic 'Possibly there are talking donkeys' which it translates (he is not committed to doing so by his analysis of modality alone, that is, by his translation of statements of quantified modal logic into counterpart theory, but he does so anyway; he thinks, like most of us, that possibility extends this far at least beyond actuality). So far there is no argument against the material or strict adequacy of the modal realist analysis. But Lewis also thinks, like most of us, that it is necessary that is possible that there is a talking donkey, and his 1968 translation of this into the language of counterpart theory, 'Every world is such that there is a world in which there is a talking donkey', is also something which he thinks is true. But the translation by Lewis's1968 rules of 'It is necessary that there is a world part of which is a talking donkey' is something he thinks false (hence on the 1968 scheme 'there is a world containing a talking donkey' is contingent since 'it is possibly true that there is a world containing a talking donkey' is true). This is 'every world has in it a world part of which is a talking donkey', which is false since parthood is transitive and not every world contains a talking donkey. So the analysandum 'Possibly there is a talking donkey' and the analysans 'There is a world part of which is a talking donkey' are not strictly equivalent (though there is no problem about material adequacy) if we take the analysis to be given by Lewis's 1968 translation scheme.

Here is another argument to the same purpose. Recall Lewis's conception of possible worlds, maximal summations of individuals related by spatiotemporal unity. This is what Lewis means by 'possible world'; the notion is not a modal one for him. So in virtue of what 'possible world' means 'there is a possible world part of which is a talking donkey' is true if and only if 'there is some spatiotemporally located object spatiotemporally related to a 
talking donkey' is true. And in virtue of what 'donkey' means it is true that any donkey, talking or otherwise, is a spatiotemporally located object. So in virtue of the meanings of 'possible world' and 'donkey' 'there is a world in which there is a talking donkey' is true if and only if 'there is a talking donkey' is true (whatever 'donkey' means this conditional is true left-to-right since 'in' denotes an extensional relation). In short, 'there is a world in which there is a talking donkey' is strictly equivalent to 'there is a talking donkey'. But according to Lewis's 1968 translation scheme 'it is necessarily true that there is a talking donkey' is false. Hence, since 'there is a talking donkey' is strictly equivalent to 'there is a possible world in which there is a talking donkey', once again the latter is not strictly equivalent to 'it is possible that there is a talking donkey' since 'it is necessarily true that it is possible that there is a talking donkey' is true by Lewis's 1968 translation scheme.

According to Divers (1999) Lewis's 1968 translation scheme should be modified as follows. We need to distinguish between two cases: ordinary and extraordinary or 'advanced' modalizing. In the ordinary cases Lewis's translation scheme should be used; in advanced cases a redundancy interpretation should be given. Ordinary modalizing is modalizing about ordinary individuals, individuals which are parts of a world (Divers 1999, p. 218), that is, have all their parts spatiotemporally related to one another. Advanced modalized is modalizing about transworld individuals (Divers 1999, p. 220). Again (and somewhat more generally) advanced modalizing takes place 'when and only when the quantification in the contained non-modal sentence is not world-restricted' (Divers 1999, p. 230). So the quantified modal statement 'it is possible that there are many worlds', which on Lewis's 1968 translation scheme is translated by a statement of counterpart theory which is false (by Lewis's lights), is translated by Divers just as 'there many worlds' (since the quantification in the contained non-modal sentence is not world-restricted), which is a true statement of counterpart theory. 
However, Divers's proposal does not restore strict adequacy to modal realist analysis unless both 'necessarily there is a world in which there is a talking donkey' and 'necessarily there is a talking donkey' are taken to be cases of advanced modalizing, in which case they both, on the redundancy interpretation, turn out to be true by modal realist lights, like 'it is necessarily true that it is possible that there is a talking donkey'.

But 'necessarily there are talking donkeys' is not an advanced modalizing claim unless the result of attaching a modal operator to any existential claim is. The modal realist and the man in the street do not differ in respect of what they mean by 'there is/are'; they differ about what things there are. So when the man in the street says that there are no talking donkeys he does not merely mean that there are none locally, that is, none spatiotemporally related to him, he means that there are none simpliciter, otherwise he should greet the modal realist's contrary contention with a yawn of indifference rather than an incredulous stare. (Contrast the man with his head in his fridge who announces that there is no beer - unless he thinks that the world is in a really bad way he means merely that there is none in the fridge not that there is none simpliciter). Similarly, when he says that there are cows, he does not mean that there are cows spatiotemporally related to him, though, of course, he believes this too, he just means that there are cows simpliciter. That is why there is a disagreement between him and the modal realist about talking donkeys; if they meant different things by 'there is/are' they would not be disagreeing. So if the quantification in the contained non-modal sentence is not world-restricted in 'necessarily there are talking donkeys' it is never world-restricted and Lewis's original 1968 translation can never be applied. This is not the result Divers intends. It is only modalizing about transworld individuals or worlds themselves that he wants to classify as cases of advanced modalizing, and not even all cases of modalizing about worlds are to count as cases of advanced modalizing. Thus Divers comments on a complaint of Yagisawa's against Lewisean realism: 
the observation that the content of modal statements about large possibilia (e.g. worlds) should be given in the same way as that of modal statements about smaller possibilia (e.g. Hubert Humphrey) ... as far as it goes is unexceptionable. Size alone shouldn't matter and ordinary modalizing about a world should be dealt with counterpart theoretically ... However, the relevant and initially problematic character of (P10) [a proposition in Yagisawa's discussion] does not consist in its being a case of modalizing about worlds, but rather in its being a case of modalizing about a transworld state of affairs. (1999, p. 235)

But none of the four statements 'necessarily/possibly there is a talking donkey' and 'necessarily/possibly there is a world in which there is a talking donkey' requires for its truth the existence of a transworld state of affairs.

Granted that the quantification within 'necessarily there are talking donkeys' does not, in the relevant sense, introduce modalizing about transworld individuals or worlds, and hence that the redundancy interpretation cannot be appealed to, the modal realist can nonetheless still argue for the strict adequacy of a modal realist analysis by maintaining that the redundancy interpretation applies to "necessarily there is a possible world in which there is a talking donkey'. Given the last quotation from Divers it is not clear how this can be justified. But suppose it can. Then the price the modal realist pays is that he cannot regard 'there is a possible world in which there is a talking donkey' and 'there is a talking donkey' as strictly equivalent despite the fact that given the meaning of 'possible world' and 'donkey' the biconditional joining them is analytically true.

\section{An alternative solution}

There is another way the modal realist can appeal to the redundancy interpretation, however. Since he is already in massive disagreement with common-sense about the existence of 
talking donkeys, it is not a great step for him to deny the contingency of their existence. But if he does this he can give what is by his lights a strictly adequate counterpart-theoretic analysis of ordinary modal discourse by giving a redundancy interpretation of all de dicto modal statements. So he can say that the analysis of the de dicto 'possibly there is a talking donkey' is 'there is a talking donkey', as is the analysis of the de dicto 'it is necessarily true that possibly there is a talking donkey'. Since he denies de dicto contingency and accepts that it is necessarily true that there is a talking donkey he can then say that the analysandum 'possibly there is a talking donkey' and the analysans 'there is a talking donkey' are not only alike in truth-value, but necessarily alike in truth-value, so the analysis is strictly as well as materially adequate.

On this account what triggers a redundancy interpretation of a modal statement is not that it is a case of advanced modalizing but that it is a de dicto modal statement. When this is not so Lewis's 1968 rules apply. So 'possibly/necessarily there is a talking donkey' is just analysed as 'there is a talking donkey', but 'there is something which is possibly a talking donkey' is analysed as 'there is something in the actual world which has a counterpart in some world which is a talking donkey, ${ }^{3}$ Now if the modal realist thinks that there is a talking donkey he must also think, by the same token, that there is something which is possibly a talking donkey. So he must accept that, by the same token, its analysis, "there is something in the actual world which has a counterpart in some world which is a talking donkey', is true. So he must accept that everything is actual, that is, that 'is actual' is coextensive with 'exists'. This is inconsistent with Lewis's account of 'actually' as an indexical. But the Lewisean account is provided merely to ensure that the commonsense man says something true when he says

\footnotetext{
${ }^{3}$ Modal operators in de re modal statements must not be interpreted as restricting quantifiers within their scope. The de re 'something is possibly a talking donkey' is to be analysed as 'there is something in the actual world and a possible world and a counterpart of it therein such that the counterpart is a talking donkey'. The de re 'something is possibly uglier than some ogre' is to be analysed as 'there is something in the actual world and a possible world and a counterpart of it therein such that that counterpart is uglier than something which is an ogre', not as '... than something which is part of that world and is an ogre'. Lewis allows $(1986$, p. 6) that modal operators need not restrict quantifiers within their scope.
} 
'there are no talking donkeys' - that there are no talking donkeys around here - though what he believes is something false by modal realist lights, that is, that there are no talking donkeys at all. This is unnecessary charity. It is like interpreting the man who really does think that there is no beer anywhere (and so none in the fridge) as meaning merely 'there is no beer in the fridge' when he says that there is no beer. The modal realist does not need to extend this charity and cannot do so whilst maintaining both that 'there are talking donkeys' is true and that the analysis of 'there are things that are possibly talking donkeys' is 'there something in the actual world which has a counterpart in some world which is a talking donkey'. But whenever charity is appropriate the de dicto contingency denying modal realist can extend it as easily as any other modal realist. The commonsense man will say both that there are not, but might have been, talking donkeys, and that there are, but might not have been, snakes (and that even if there had been talking donkeys there might not have been). Any modal realist should say that the first claim, as the commonsense man intends it, is necessarily false (since the commonsense man does not intend any quantifier restriction). ${ }^{4}$ But the de dicto contingency denying modal realist can interpret the commonsense man's second claim as expressing a truth as easily as any other modal realist. According to him our world might have been free of snakes (it has a counterpart - Ireland or a duplicate - which is), or equivalently expressed without reference to a world, of any spatiotemporal region we inhabit it is true that it might have been free of snakes. So he can charitably interpret the commonsense man's claim that there might have been no snakes as expressing a de re truth rather than a de dicto falsehood. He need not slavishly follow the division of vernacular modal statements into de re and de dicto which translation into the language of boxes and diamonds imposes. His disagreement with commonsense therefore need be no more extreme than that of any other modal realist.

\footnotetext{
${ }^{4}$ Lewis (1986, p. 99). Of course he intends only to be speaking of what is actual but he does not think of that as a restriction.
} 
Denying de dicto contingency and extending the redundancy interpretation to all de dicto modal statements does not solve all the problems for modal realist analysis however. Since the modal realist thinks that there are spatiotemporally unrelated things, he must accept that there are things of which it is possible that they are spatiotemporally unrelated. But on Lewis's 1968 analysis this requires that there is a world in which they have spatiotemporally unrelated counterparts. There is no such world. The way forward, I think, it is to recognise that not all counterparts are parts of a world. Some are too big. Lewis says that I could have been a poached egg. If so I surely could have been an individual with spatiotemporally unrelated parts. (I have a near duplicate counterpart who lives just a second longer than me. The sum of the last second stage of that counterpart and me is surely as similar to me as a poached egg is under some similarity relation employable as a counterpart relation.) So if counterpart theory is right I have a transworld individual as a counterpart. Similarly a pair of unrelated individuals has a counterpart pair - itself, at least - which is a pair of unrelated individuals. ${ }^{5}$ If the redundancy interpretation of de dicto modal statements is accepted, then, the interpretation of de re modal statements should also be modified to dispense with quantification over, and restriction to the parts of, worlds. Thus 'there is something which is possibly a talking donkey' should be analysed as 'something has a talking donkey as a counterpart'. Possible worlds then drop out of the modal realist account of modal discourse both in the case of statements of de dicto and in the case of statements of de re modality (whether they are required elsewhere is another matter). A scheme for translating statements in the language of boxes and diamonds into counterpart theory discourse that conforms to this perspective is as follows. Given a statement in the language of quantified modal logic (a)

\footnotetext{
${ }^{5}$ Counterparts of pairs have to be distinguished from pairs of counterparts as Lewis explains (1983, p. 44). I might have been taller than I am. I have a counterpart who is taller than me. But it is not the case that it might have been that I was taller than I was (as it might have been that my brother was taller than I was) even though I have multiple counterparts - even ones inhabiting a single possible world - differing in height. No such pair of counterparts is a counterpart of the pair <me, myself>, or at least not one relevant to the evaluation of the modal statement 'It might have been that I was taller than I was'.
} 
drop all modal operators not within the scope of quantifiers, then (b) beginning with innermost occurrences, replace $\nabla \varphi \alpha_{1} \ldots \alpha_{n} / \square \varphi \alpha_{1} \ldots \alpha_{n}$, in which $\alpha_{1} \ldots \alpha_{n}$ are free, with, respectively, $\exists \gamma_{1} \ldots \exists \gamma_{\mathrm{n}}\left(C \gamma_{1} \alpha_{1} \& \ldots \& C \gamma_{n} \alpha_{n} \& \varphi \gamma_{1} \ldots \gamma_{n}\right)$ and $\forall \gamma_{1} \ldots \forall \gamma_{n}\left(C \gamma_{1} \alpha_{1} \& \ldots \&\right.$ $\mathrm{C} \gamma_{\mathrm{n}} \alpha_{\mathrm{n}} \rightarrow \varphi \gamma_{1} \ldots \gamma_{\mathrm{n})}$ in which $\gamma_{1}, \ldots, \gamma_{\mathrm{n}}$ are new.

\section{Conclusion}

I have argued that if he denies de dicto contingency and gives a redundancy interpretation of all de dicto modal statements the modal realist can maintain that his analysis of modal discourse is strictly adequate. The alternative is for the modal realist to accept, with Lewis in 1968 , that his analysis is materially adequate but not strictly adequate. 'Possibly there is a talking donkey' and 'there is a world in which there is a talking donkey' are alike in truthvalue, but 'it is necessarily true that it is possible that there is a talking donkey' and 'it is necessarily true that there is a world in which there is a talking donkey' differ in truth-value. The former is true and the latter false. So, just as it is contingent whether there is a talking donkey, it is contingent whether there is a world in which there is a talking donkey (since it is possibly true that there is a world in which there is a talking donkey).

The merely contingent existence of a world in which there is a talking donkey may seem hard to swallow. But we have no choice if we accept (a) that it is necessarily true that if there is a world in which there is a talking donkey there is a talking donkey, (b) that if so and it is necessarily true that there is a world in which there is a talking donkey it is a necessary truth that there is a talking donkey and (c) that it is not a necessary truth that there is a talking donkey.

In sum, since any truth is necessary or contingent any modal realist is obliged to say, of any biconditional linking a modal claim with its purported content-giving equivalent in the language of counterpart theory, which of these it is. Lewis's 1968 translation scheme 
commits him to answering 'contingent'. Later he seems inclined to answer 'necessary'

(Lewis 1986, pp. 111 - 12 and Lewis 1996) and to be willing to pay the price of holding these biconditionals necessary, namely the abandonment of de dicto contingency. ${ }^{6}$ But once de dicto_contingency is abandoned reference to possible worlds, as opposed to smaller and larger possibilia, no longer has to have a distinguished role in a modal realist account of everyday modal discourse. ${ }^{7}$

Department of Philosophy

HAROLD W. NOONAN

The University of Nottingham

Nottingham

Harold.noonan@nottingham.ac.uk

\section{References}

Divers, John 1999: 'A genuine modal realist theory of advanced modalizing'. Mind, 108, pp. $217-39$.

Dorr, Cian unpublished: 'Modal realism'. <http://users.ox.ac.uk/ sfop0257/papes/ModalRealism.pdf>

\footnotetext{
${ }^{6}$ Lewis (1986:211) says that the statement of our 'contingent knowledge' is the indexical 'that there are donkeys at our_world' (Lewis's emphases). So its (false) necessitation is a de re modal claim about our world, not a de dicto modal claim. The modal realist who, unlike Lewis in 1968, affirms the necessity not only of 'Possibly there is a talking donkey' but also of 'if it is possible that there is a talking donkey there is some world which has a talking donkey in it', together with the contingency of 'there is a talking donkey', cannot be interpreted as consistent, no matter how loosely (following Lewis 1986, p. 6) we interpret the restrictions imposed by his modal operators on quantifiers within their scope, i.e. no matter how generously we understand ' $x$ is in $w$ ' (even if we read it just as ' $x$ exists and $w$ exists'), unless he is interpreted as rejecting the necessity of 'if there is some world which has a talking donkey in it then there is a talking donkey'. But to interpret him so we must read his 'there is a talking donkey' as meaning 'there is a talking donkey in our world' and then affirming its contingency is not affirming a de dicto contingency.

${ }^{7}$ I am grateful to several referees and my colleague, Mark Jago, for comments. I am also grateful to Dan Marshall for reading a draft of the paper for Mind and drawing my attention to his unpublished paper 'A puzzle for modal realism' and related unpublished papers by Cian Dorr and Josh Parsons.
} 
Lewis, David 1968: 'Counterpart theory and quantified modal logic'. The Journal of Philosophy, 65, $113-26$.

----- 1983: Philosophical Papers. Oxford: Oxford University Press.

----- 1986: On the Plurality of Worlds. Oxford: Basil Blackwell.

1996: ‘Maudlin and modal mystery'. Australasian Journal of Philosophy,

74 , pp. $683-4$

Marshall, Daniel unpublished: 'A puzzle for modal realism'.

Noonan, Harold 1994: 'In defence of the letter of fictionalism'. Analysis, 54, pp. 133 - 9.

Parsons, Josh unpublished: 'Against advanced modalizing'.

<http://puketo.otago.ac.nz/ jp30/papers/against-advanced2.pdf> 